\title{
Solvent Extraction of Lanthanides(III) in the Presence of the Acetate Ion Acting as a Complexing Agent Using Mixtures of Cyanex 272 and Caprylic Acid in Hexane
}

\author{
Vera V. Belova, Yulia V. Tsareva, Yulia A. Zakhodyaeva, Vladimir K. Ivanov (D) and Andrey A. Voshkin *(D)
}

check for updates

Citation: Belova, V.V.; Tsareva, Y.V.; Zakhodyaeva, Y.A.; Ivanov, V.K.; Voshkin, A.A. Solvent Extraction of Lanthanides(III) in the Presence of the Acetate Ion Acting as a Complexing Agent Using Mixtures of Cyanex 272 and Caprylic Acid in Hexane. Processes 2021, 9, 2222. https:// doi.org/10.3390/pr9122222

Academic Editor:

Salman Masoudi Soltani

Received: 4 November 2021

Accepted: 7 December 2021

Published: 9 December 2021

Publisher's Note: MDPI stays neutral with regard to jurisdictional claims in published maps and institutional affiliations.

Copyright: (c) 2021 by the authors. Licensee MDPI, Basel, Switzerland. This article is an open access article distributed under the terms and conditions of the Creative Commons Attribution (CC BY) license (https:/ / creativecommons.org/licenses/by/ $4.0 /)$.
Kurnakov Institute of General and Inorganic Chemistry, Russian Academy of Sciences, 31 Leninsky Prospect, 119991 Moscow, Russia; belova@igic.ras.ru (V.V.B.); tsareva.juliana@yandex.ru (Y.V.T.); yz@igic.ras.ru (Y.A.Z.); van@igic.ras.ru (V.K.I.)

* Correspondence: voshkin@igic.ras.ru; Tel.: +7-495-9542442

Abstract: A new extraction system containing a mixture of Cyanex 272 and caprylic acid is proposed for the extraction and separation of lanthanides(III). It was shown that this system possesses a high level of extraction ability and capacity. The extraction of lanthanides(III) from chloride-acetate and nitrate-acetate media was investigated on an example of $\mathrm{La}(\mathrm{III})$. The composition of the extracted species was confirmed, based on the analysis of lanthanum(III) extraction isotherms. In the case of acetic-acetate aqueous solutions, a decrease in lanthanum(III) extraction efficiency was observed, due to the decreasing equilibrium $\mathrm{pH}$ of the aqueous phase in accordance with the cation-exchange mechanism. The composition of the synergistic mixture of Cyanex 272-caprylic acid established demonstrates highly efficient separation of rare-earth metal ions.

Keywords: solvent extraction; lanthanides(III); Cyanex 272; caprylic acid

\section{Introduction}

Rare earth elements (REE) find their application in many fields of advanced materials science and industry as they demonstrate a variety of promising and unique properties (for example, luminescent, electronic, magnetic, and catalytic properties) [1-5].

The separation of lanthanides is a challenging goal, due to their similar chemical and physical behavior. In recent years, there have been a growing number of studies on the recovery and separation of lanthanides using a variety of methods, among which special attention has been paid to liquid-liquid extraction [6-11]. Liquid-liquid extraction is the most common large-scale separation method, which is usually carried out as a continuous, multi-stage process of extraction and separation of REE from aqueous solutions using an organic solvation agent (extractant) that forms complexes with REE ions. Rare earth metals are then stripped from the REE-enriched organic phase by putting it in contact with an aqueous solution with which ions have a greater affinity. Due to the very small behavioral difference between lanthanides, the extraction-stripping process should be repeated multiple times to achieve satisfactory separation. Usually, solvent extraction is followed by precipitation of REE as a salt (e.g., carbonate, oxalate) or hydroxide, filtering, washing, drying (or calcination) and grinding. Extractants of various classes have recently been used for REE extraction and separation, for example, organophosphorus cation-exchange extractants [12-15], neutral extractants (e.g., TBP, trialkylphosphine oxides) [16-19], binary extractants and ionic liquids [20-26].

The most widely used acidic organophosphorus extractants for REE are 2-ethylhexylphosphonic acid mono-2-ethylhexyl ester (EHEHPA), di(2,4,4-trimethylpentyl)phosphinic acid (Cyanex 272) and di(2-ethylhexyl)phosphoric acid (DEHPA) [27-30]. Previously, the extraction of REE from chloride solutions was studied using organophosphorus acids 2ethylhexylphosphonic acid mono-(2-ethylhexyl) ester (HEHEHP) combined with DEHPA, 
isopropylphosphonic acid 1-hexyl-4-ethyloctyl ester, Cyanex 272, bis(2,4,4-trimethypentyl)monothiophosphinic acid (Cyanex 302) or bis(2,4,4-trimethypentyl)dithiophosphinic acid (Cyanex 301) as extractants. It was found that HEHEHP and Cyanex 272 could be used for the separation of $\mathrm{Tm}(\mathrm{III}), \mathrm{Yb}(\mathrm{III})$ and $\mathrm{Lu}(\mathrm{III})$ from the other rare earth elements [27]. Acidic extractants are usually saponified in the organic phase by the addition of bases, in order to speed up the extraction, and then REE are stripped from the organic phase using acidic aqueous solutions during the subsequent step. Synergistic extraction of heavy REE was observed in chloride media when mixing (2-ethylhexylamino)methylphosphonic acid mono-2-ethylhexyl ester (HEHAMP) and EHEHPA. The maximum synergistic enhancement factors of $\mathrm{Lu}(\mathrm{III}), \mathrm{Yb}(\mathrm{III}), \mathrm{Tm}(\mathrm{III}), \mathrm{Er}(\mathrm{III}), \mathrm{Y}(\mathrm{III})$ and $\mathrm{Ho}$ (III) were 2.89, 2.76, 2.54, 2.14, 2.14 and 2.06, respectively, at a mole fraction of HEHAMP equal to 0.5 [28]. Different extractants and their mixtures were investigated for $\operatorname{Pr}(\mathrm{III})$ extraction from chloride media [29]. Among all the combinations, mixtures of Cyanex 301 with Cyanex 921 or Cyanex-923 demonstrated a synergistic effect on the extraction of praseodymium. Different extractants (Cyanex 272, DEHPA, EHEHPA and Cyanex 301) were tested for the separation of La from Pr and Nd from synthetic chloride leach liquor [30]. Cyanex 272 demonstrated a better extraction affinity toward $\mathrm{Pr}$ and $\mathrm{Nd}$ than La. Saponification of Cyanex 272 favored the separation of La from Pr and Nd.

The practical application of Cyanex 272 is restricted by its low loading capacity, because of its high $\mathrm{pK}_{\mathrm{a}}$ value [31], and the low lipophilicity of the extracted species. In this regard, a number of synergistic extractant systems have been suggested for overcoming the low extractability of Cyanex 272 and much attention has been paid to systems containing several extractants. Thus, the synergistic extraction of $\mathrm{Pr}$ and $\mathrm{Nd}$ was achieved with the binary mixtures of Cyanex 272 and tertiary amines [31-33]. Among the extractant mixtures studied, the combination of Cyanex 272 and Alamine 336 showed the best extraction ability, and the highest synergistic enhancement factors were observed at a Cyanex 272 mole fraction of 0.5. The quantitative stripping of REE from the organic phase was found to be possible by using solutions of mineral acids. A binary extractant based on Cyanex 272 and methyltrioctylammonium showed a high extraction ability for REE recovery from nitrate media [24]. In the extraction of light REE, a synergistic effect was found in the case of a Cyanex 272-EHEHPA system with a low acid concentration [34]. Synergistic extraction of REE was observed while using mixtures of bis(2,4,4-trimethylpentyl)phosphinic acid with 8-hydroxyquinoline [35] and with sec-nonylphenoxy acetic acid [36]. The mixture of DEHPA and Cyanex 272 was found to be synergistic for Eu(III) extraction. In the extraction studies, the maximum synergistic enhancement factor was obtained for the DEHPA-Cyanex 272 mixture with a 1:1 molar ratio [37].

As well as using synergistic systems, the extraction and separation of REE can be significantly improved by the addition of complexing agents to the aqueous phase. For example, the extraction and separation of $\operatorname{Pr}(\mathrm{III})$ and Ce(III) in the EHEHPA-containing system was found to become more efficient in the presence of complexing agents, such as lactic or citric acid [38]. The addition of lactic acid to the DEHPA-containing system was accompanied by an increase in DEHPA extraction capacity [39]. It was found that the use of acetic acid, along with lactic acid, promoted the extraction of REE by Cyanex 272 in kerosene [40]. The extraction of $\mathrm{La}(\mathrm{III})$ from acidic nitrate-acetate media by Cyanex 272 $\left(\mathrm{H}_{2} \mathrm{~A}_{2}\right)$ alone, or in combination with trioctylphospine oxide (TOPO) $(\mathrm{B})$ in toluene, was investigated [41]. It was found that $\left[\mathrm{La}(\mathrm{OAc})_{2} \mathrm{~A} \cdot 3 \mathrm{HA}\right]$ and $\left[\mathrm{La}(\mathrm{OAc}) \mathrm{A}_{2} \cdot \mathrm{B}\right]$ are extracted in systems without and with TOPO, respectively.

In the case of $\mathrm{Nd}^{3+}$, Zanonato [42] demonstrated that lanthanide ions form various acetate complexes according to the following equilibrium:

$$
\mathrm{Ln}^{3+}+\mathrm{j}(\mathrm{OAc})^{-} \leftrightarrows \mathrm{Ln}(\mathrm{OAc})_{\mathrm{j}}{ }^{(3-\mathrm{j})+}, \mathrm{j}=1,2,3
$$

It has been reported that the extraction of REEs by the binary extractants is improved in the presence of carboxylates due to the solvation of extracted species in the organic phase $[43,44]$. Thus, the mixture of Cyanex 272 with caprylic acid was examined to 
improve the solubility of lanthanum extracted complexes. The availability of acetic acid, in combination with its low price, makes it suitable for extraction purposes. Thus, the acetate ion was used as a complexing agent in the experimental study described below. This paper describes a new Cyanex 272-caprylic acid system for the extraction of lanthanides(III) from chloride-acetate and nitrate-acetate solutions. La(III) was chosen as a model object.

\section{Materials and Methods}

Stock solutions of lanthanum(III) chloride and nitrate were prepared by dissolving $\mathrm{LaCl}_{3} \cdot 7 \mathrm{H}_{2} \mathrm{O}$ and $\mathrm{La}\left(\mathrm{NO}_{3}\right)_{3} \cdot 6 \mathrm{H}_{2} \mathrm{O}$ in distilled water. Stock solutions of $\mathrm{Nd}, \mathrm{Eu}, \mathrm{Dy}, \mathrm{Er}$ and $\mathrm{Yb}$ chlorides were prepared from their oxide (>99.9\%) by dissolving them in $\mathrm{HCl}$ (conc.) and diluting to the required volume with distilled water. The initial aqueous solutions were diluted to the desired lanthanide concentration. Selected concentrations of acetate ions in aqueous solutions were maintained by adding $\mathrm{NaOAc}$ or $\mathrm{AcOH}$.

A mixture of di(2,4,4-trimethylpentyl)phosphinic acid (Cyanex 272, CYTEC, Canada) and caprylic acid (Acros) was used as an extractant (solution in hexane). Commercial extractants were used without any further purification.

The concentrations of lanthanide in the initial solution and in the aqueous phase after extraction were determined via titration with a standard solution of EDTA at $\mathrm{pH}$ 5.5, using xylenol orange as an indicator. The concentration of lanthanide in the organic phase was calculated as the difference between the concentrations in the initial solution, and the aqueous phase, after extraction. The concentrations of lanthanide in the organic phase were also determined after its stripping with $0.5 \mathrm{~mol} / \mathrm{L} \mathrm{HCl}$ solution. Reagent grade chemicals were used. The distribution ratio (D) was determined as the ratio of the concentration of lanthanide(III) in the organic phase to that in the aqueous phase, and was calculated according to the following equation:

$$
\mathrm{D}=[\mathrm{Ln}]_{\mathrm{o}} /[\mathrm{Ln}]_{\mathrm{aq}}
$$

where $[\mathrm{Ln}]_{\mathrm{o}}$ and $[\mathrm{Ln}]_{\mathrm{aq}}$ are the equilibrium concentrations of the lanthanide in the organic and aqueous phase, respectively. The separation factor characterizes the separation degree between two lanthanides $\left(\mathrm{Ln}^{1}-\mathrm{Ln}^{2}\right)$ in the extraction system and was calculated according to the following equation:

$$
\beta=\mathrm{D}\left(\operatorname{Ln}^{2}\right) / \mathrm{D}\left(\operatorname{Ln}^{1}\right)
$$

Extraction was performed at $20^{\circ} \mathrm{C}$ in test tubes with ground-in stoppers, with equal volumes of the aqueous and the organic phases. Phases were mixed for $15 \mathrm{~min}$, which was sufficient to establish the permanent values of the distribution ratios of lanthanides. $\mathrm{pH}$ measurements were performed using a SevenExcellence s470-k pH meter.

Three replicate experiments showed that the standard deviation of the measurements was less than $5 \%$.

\section{Results and Discussion}

Preliminary experiments indicated that the extraction of $\mathrm{La}$ (III) from chloride-acetate solutions with a $0.015 \mathrm{~mol} / \mathrm{L}$ Cyanex 272 solution in hexane was accompanied by the formation of insoluble products. To increase the solubility of lanthanum extracted species, hexane solutions of Cyanex 272 were supplemented with caprylic acid in different concentrations (vide infra). The introduction of the latter resulted in complete precipitation suppression. The structure of the extractants is shown in Figure 1. 


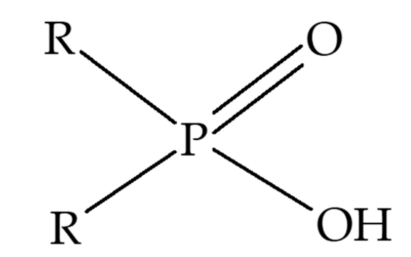<smiles>CCCCCCC(=O)O</smiles><smiles>CCC(C)CC(C)(C)CC</smiles>

Figure 1. Commercial extractants Cyanex 272 and caprylic acid.

\subsection{Effect of Caprylic Acid Concentration}

Figure 2 shows evidence, from experimental data, for the effect of caprylic acid concentration on $\mathrm{La}(\mathrm{III})$ extraction from chloride-acetate solution $(0.1 \mathrm{~mol} / \mathrm{L} \mathrm{NaOAc}$; $C_{\mathrm{La}(\text { init) }}=0.02 \mathrm{~mol} / \mathrm{L}$ ), both for pure acid and its mixture with Cyanex 272. In the first case (curve 1, pure acid), the distribution ratios of $\mathrm{La}(\mathrm{III})$ did not exceed 0.6 , despite the increase of the concentration of caprylic acid to $0.05 \mathrm{~mol} / \mathrm{L}$. The use of caprylic acid in combination with Cyanex 272 led to a significant growth in the La(III) distribution ratios (curve 2). In this case, extraction efficiency improved noticeably with an increase in the caprylic acid concentration. It can be assumed that extractable compounds with a different composition were formed in the system, involving a mixture of Cyanex 272 and caprylic acid, compared to extraction with pure extractants.

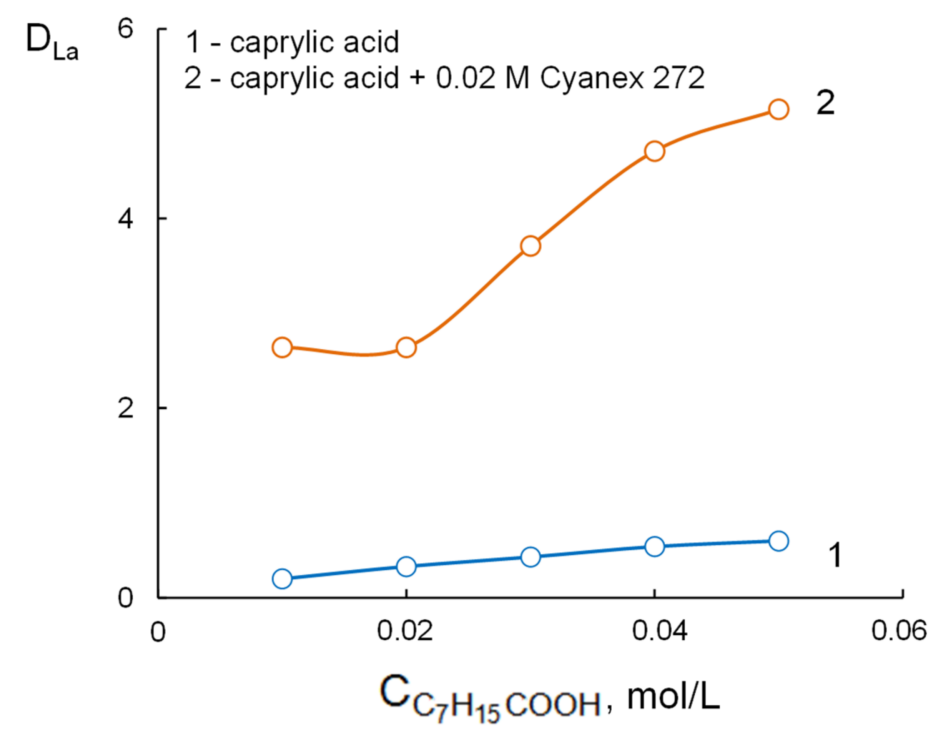

Figure 2. Effect of caprylic acid concentration on the $\mathrm{La}(\mathrm{III})$ extraction.

\subsection{Effect of Sodium Acetate Concentration}

Sodium acetate concentration was found to affect, to some extent, $\mathrm{La}(\mathrm{III})$ extraction from chloride-acetate and nitrate-acetate solutions $\left(\mathrm{C}_{\mathrm{La} \text { (init) }}=0.02 \mathrm{~mol} / \mathrm{L}\right)$ with a mixture of Cyanex $272(0.015 \mathrm{~mol} / \mathrm{L})$ and caprylic acid $(0.02 \mathrm{~mol} / \mathrm{L})$ in hexane (Figure 3). In particular, an increase in $\mathrm{NaOAc}$ concentration caused a substantial increase in the distribution ratio of lanthanum until reaching a NaOAc:La ratio of about 10:1, after which no significant changes were observed. It is also noteworthy that the equilibrium $\mathrm{pH}$ value of the aqueous phase grew together with the efficiency of the $\mathrm{La}(\mathrm{III})$ transfer to the organic phase. 


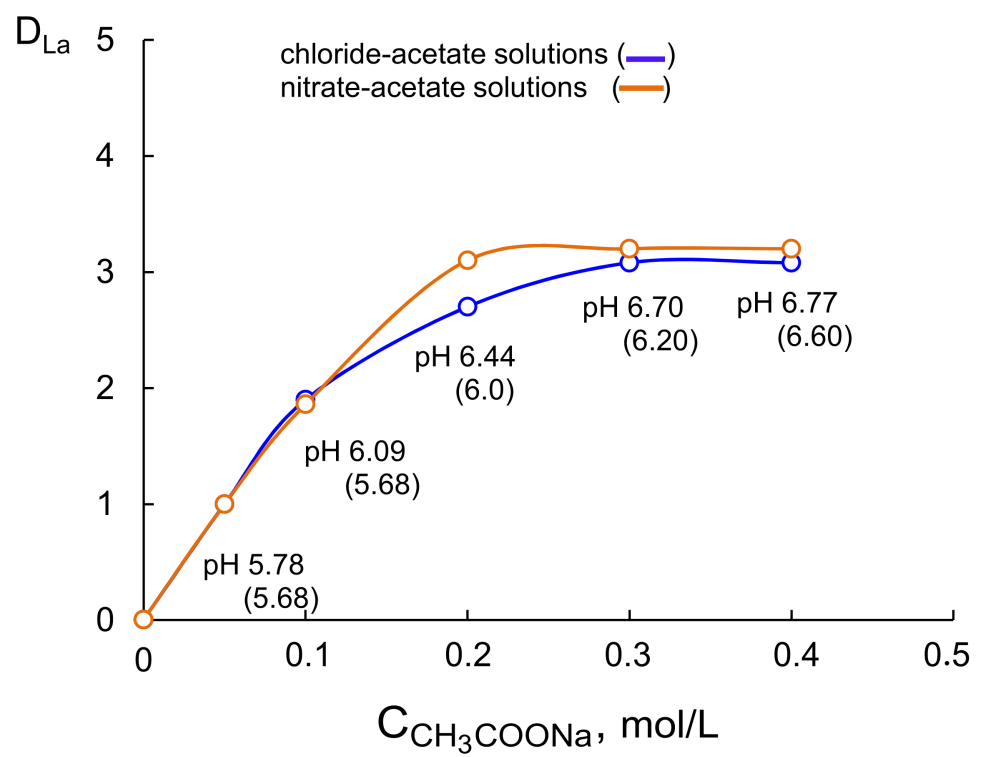

Figure 3. Effect of $\mathrm{NaOAc}$ concentration on the $\mathrm{La}(\mathrm{III})$ extraction.

When studying the complexation of $\mathrm{Nd}(\mathrm{III})$ with the acetate ion in aqueous solutions, Zanonato [42] observed the formation of stable complex cations $\mathrm{Nd}(\mathrm{OAc})^{2+}$ when the ratio of acetate to metal was equal to 10 or more at $25^{\circ} \mathrm{C}$. It can be inferred that under corresponding experimental conditions complex cations such as $\mathrm{La}(\mathrm{OAc})^{2+}$ are also the most stable species; thus, an increase in the sodium acetate concentration to more than $0.2 \mathrm{~mol} / \mathrm{L}$ (when the ratio of sodium acetate to lanthanum reached 10) did not lead to the further $\mathrm{D}_{\mathrm{La}}$ increase (Figure 3).

To establish a synergistic effect in the system containing mixtures of Cyanex 272 and caprylic acid, a study of $\mathrm{La}$ (III) distribution was carried out in the case of chloride-acetate solutions $\left(0.1 \mathrm{~mol} / \mathrm{L} \mathrm{NaOAc} ; \mathrm{C}_{\mathrm{La} \text { (init) }}=0.02 \mathrm{~mol} / \mathrm{L}\right)$ using isomolar mixtures of Cyanex 272 and caprylic acid, depending on the molar fraction of Cyanex 272 in the organic phase (Figure 4). It can be noted that an increase in the molar fraction of Cyanex 272 in the mixture of extractants led to a monotonous increase in the lanthanum distribution ratios, indicating the predominant formation of lanthanum complexes with this extractant.

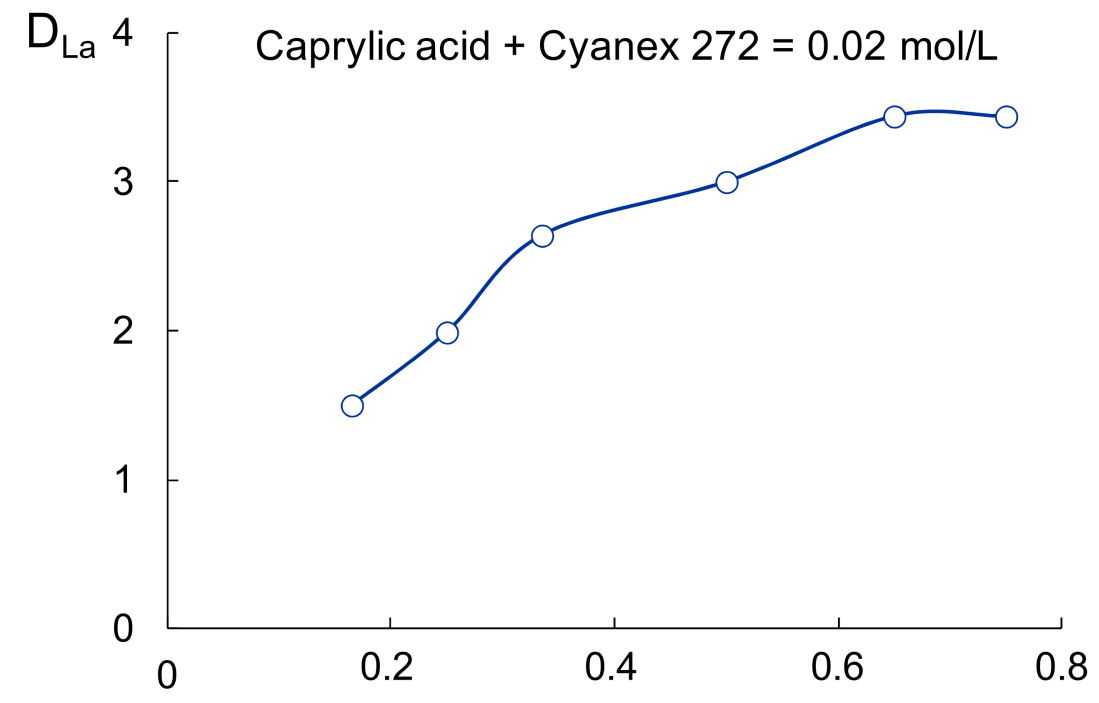

Fraction of Cyanex 272

Figure 4. Effect of molar fraction of Cyanex 272 on the La(III) extraction. 


\subsection{Extraction Isotherms for $\mathrm{La}(I I I)$}

Figure 5 shows the extraction isotherms of $\mathrm{La}(\mathrm{III})$ from chloride-acetate $(1,2)$ and nitrate-acetate (3) solutions obtained at various initial concentrations of Cyanex 272 (mol/L: 0.01 (1), 0.015 (2), 0.012 (3)) and caprylic acid (mol/L: $0.015(1,3), 0.03$ (2)) under conditions of caprylic acid excess. The extraction isotherms obtained were characterised by high distribution ratios of $\mathrm{La}(\mathrm{III})$ in the initial regions (Figure 5), indicating the high extraction ability of the proposed mixtures. Under saturation conditions, the concentration of La in the organic phase was close to the initial concentration of Cyanex 272, during extraction from both chloride-acetate and nitrate-acetate solutions (Figure 5), i.e., the ratio of $\mathrm{C}_{\mathrm{La}(\mathrm{o})}: \mathrm{C}_{\mathrm{Cyanex} \text { (init.) }}$ 1. A double increase in the caprylic acid concentration (from 0.015 to $0.03 \mathrm{~mol} / \mathrm{L}$ ) at an initial Cyanex 272 concentration of $0.01 \mathrm{~mol} / \mathrm{L}$ (Figure 5, curves 1, 2) did not lead to an increase in the La concentration in the organic phase. Thus, the data obtained from the extraction isotherms (Figure 5) and the isomolar series (Figure 4) confirm the formation of $\mathrm{La}(\mathrm{III})$ extracted species in the organic phase, mainly with Cyanex 272. It can be assumed that caprylic acid molecules solvated the extracted species, increasing their solubility in the organic phase as, in the absence of caprylic acid, the extraction of $\mathrm{La}$ (III) with Cyanex 272 was accompanied by precipitation. The solvate formation in the organic phase not only improved the solubility of the extracted complexes but also increased their thermodynamic stability, since the $\mathrm{La}(\mathrm{III})$ distribution ratios increased with caprylic acid concentration (Figure 2).

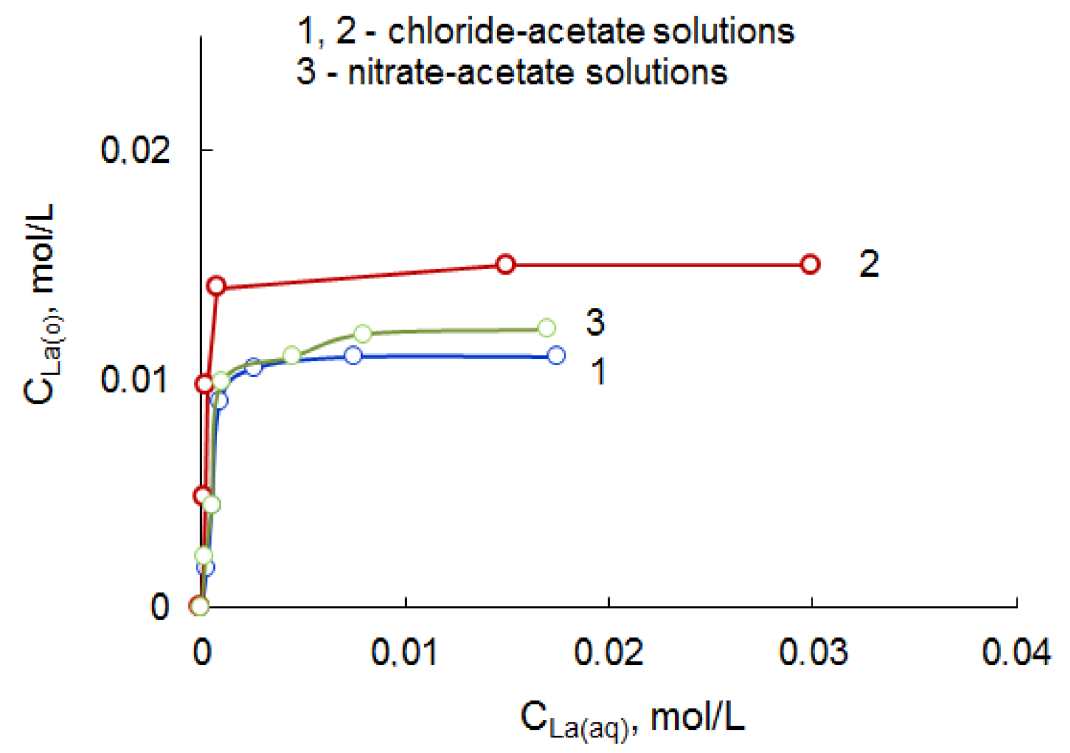

Figure 5. Isotherms of $\mathrm{La}(\mathrm{III})$ extraction with Cyanex 272-caprylic acid mixtures.

Based on the literature data on the composition of $\mathrm{La}(\mathrm{III})$ complexes in acetate solutions [42], these experimental results allow us to suggest that the extraction of $\mathrm{La}(\mathrm{III})$ from chloride-acetate and nitrate-acetate solutions in the presence of Cyanex $272\left(\mathrm{H}_{2} \mathrm{~A}_{2}\right)$ and caprylic acid $\left(\mathrm{H}_{2} \mathrm{~B}_{2}\right)$ (which are usually dimeric in nonpolar solvents) mixtures proceeded according to the cation-exchange mechanism and can be described by the equilibrium below:

$$
\mathrm{La}(\mathrm{OAc})_{2}{ }_{(\mathrm{aq})}+0.5 \mathrm{H}_{2} \mathrm{~A}_{2(\mathrm{o})}+\mathrm{s} \mathrm{H}_{2} \mathrm{~B}_{2(\mathrm{o})} \leftrightarrows \mathrm{La}(\mathrm{OAc})_{2} \mathrm{~A} \cdot \mathrm{sH}_{2} \mathrm{~B}_{2(\mathrm{o})}+\mathrm{H}^{+}{ }_{(\mathrm{aq})}
$$

where aq and o stand for the aqueous and the organic phases, respectively, and $\mathrm{s}$ is the number of caprylic acid dimers in solvates. Thus, an increase in $\mathrm{D}_{\mathrm{La}}$ values, with an increase in the concentration of $\mathrm{NaOAc}$ (Figure 3), is associated both with increasing the acetate ion concentration in the aqueous phase, and with the growth of equilibrium $\mathrm{pH}$ in accordance with the above equation. 


\subsection{Extraction in the Presence of $\mathrm{NaOAc/AcOH}$ Mixtures}

High distribution ratios of $\mathrm{La}$ (III) for chloride-acetate and nitrate-acetate solutions in systems containing Cyanex 272-caprylic acid mixtures complicate the separation of lanthanides; therefore, the extraction of lanthanum and neodymium from aqueous solutions in the presence of mixtures of sodium acetate and acetic acid were examined. The experimental conditions were as follows: aqueous phase $-\mathrm{NaOAc}+\mathrm{AcOH}=0.2 \mathrm{~mol} / \mathrm{L} ; \mathrm{C}_{\mathrm{Ln} \text { (init) }}=0.01 \mathrm{~mol} / \mathrm{L}$; or ganic phase $-0.01 \mathrm{~mol} / \mathrm{L}$ Cyanex 272 (a, b); $0.02 \mathrm{~mol} / \mathrm{L}$ (a), $0.15 \mathrm{~mol} / \mathrm{L}$ (b) caprylic acid. The equilibrium $\mathrm{pH}$ values are given in Figure 6. The data for isomolar series (Figure 6) showed that the distribution ratios of lanthanides decreased with a reduction in the molar fraction of $\mathrm{NaOAc}$ in a mixture because of the equilibrium $\mathrm{pH}$ of the aqueous phase decreasing with the addition of acetic acid in accordance with the cation-exchange mechanism of the extraction. Experimental data (Figure 6) show that for extraction from nitrate acetic-acetate solutions distribution ratios for $\mathrm{Nd}(\mathrm{III})$ were higher than for lanthanum.

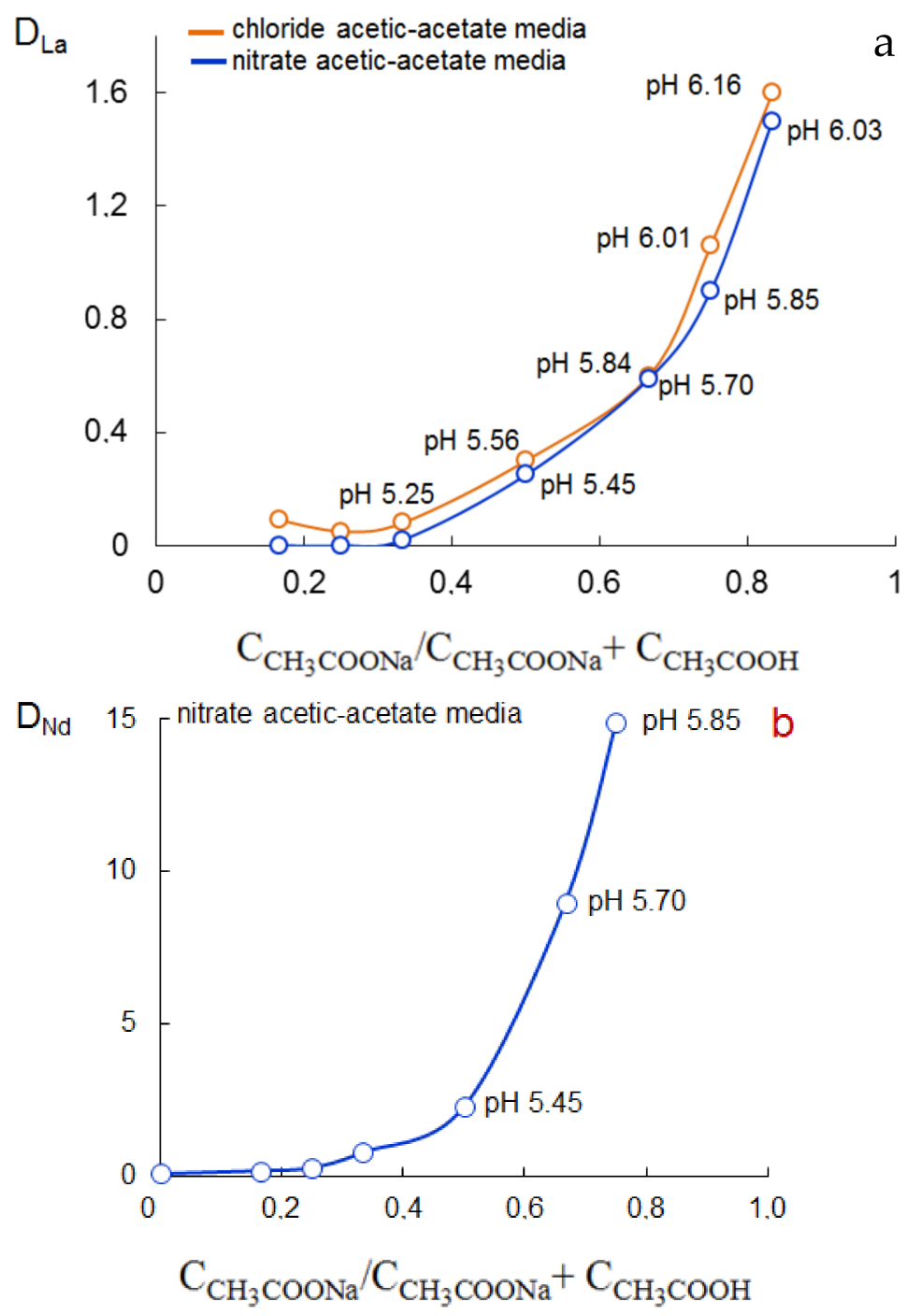

Figure 6. Effect of the molar fraction of NaOAc on the extraction of $\mathrm{La}(\mathrm{III})$ (a) and $\mathrm{Nd}(\mathrm{III})$ (b).

The distribution ratios of lanthanides(III) for chloride acetic-acetate solutions at $\mathrm{C}_{\mathrm{CH}_{3} \mathrm{COOH}}+\mathrm{C}_{\mathrm{CH}_{3} \mathrm{COOH}}=0.2 \mathrm{~mol} / \mathrm{L}$ in the aqueous phase, during extraction with a mixture containing $0.01 \mathrm{~mol} / \mathrm{L}$ Cyanex 272 and $0.15 \mathrm{~mol} / \mathrm{L}$ caprylic acid in hexane, are presented in Table 1. These results show a decrease in the distribution ratios of lanthanides(III) with an increase in the molar fraction of acetic acid in the mixture, as do the data in Figure 6. 
Table 1. Distribution ratios of lanthanides(III) for chloride acetic-acetate solutions (eq.- equal).

\begin{tabular}{|c|c|c|c|c|c|c|}
\hline \multirow{3}{*}{ Ln } & \multicolumn{6}{|c|}{ NaOAc:AcOH } \\
\hline & \multicolumn{2}{|c|}{ 1:1 } & \multicolumn{2}{|c|}{ 1:1.4 } & \multicolumn{2}{|c|}{$1: 2$} \\
\hline & $D_{\text {Ln }}$ & pH eq. & $D_{\text {Ln }}$ & $\mathrm{pH}$ eq. & $D_{\text {Ln }}$ & $\mathrm{pH}$ eq. \\
\hline $\mathrm{Nd}$ & 4.46 & 5.55 & 2.33 & 5.30 & 1.35 & 5.15 \\
\hline $\mathrm{Sm}$ & 4.98 & 5.55 & 3.35 & 5.30 & 1.86 & 5.15 \\
\hline Dy & 5.67 & 5.55 & 4.0 & 5.30 & 2.10 & 5.15 \\
\hline
\end{tabular}

It is possible to affect the distribution and separation of REE by changing the composition of the aqueous phase, for example, by varying the ratio of $\mathrm{NaOAc}$ and $\mathrm{AcOH}$. Thus, the system containing a mixture of Cyanex 272 and caprylic acid can be used for the efficient extraction of the sum of lanthanides(III) from acetate solutions.

\subsection{Extraction of Lanthanides(III) from Chloride and Nitrate Acetic-Acetate Solutions}

Since the distribution ratios of lanthanides are reduced for acetic acid solutions, the extraction of these metals from chloride and nitrate acetic-acetate solutions was studied, in order to determine the possibility of their separation. The distribution ratios of lanthanides(III) during extraction from chloride and nitrate acetic-acetate solutions with a mixture of Cyanex 272 and caprylic acid at $1 / 3$ and $1 / 2$ in hexane are given in Figure 7 and Table 2, respectively.

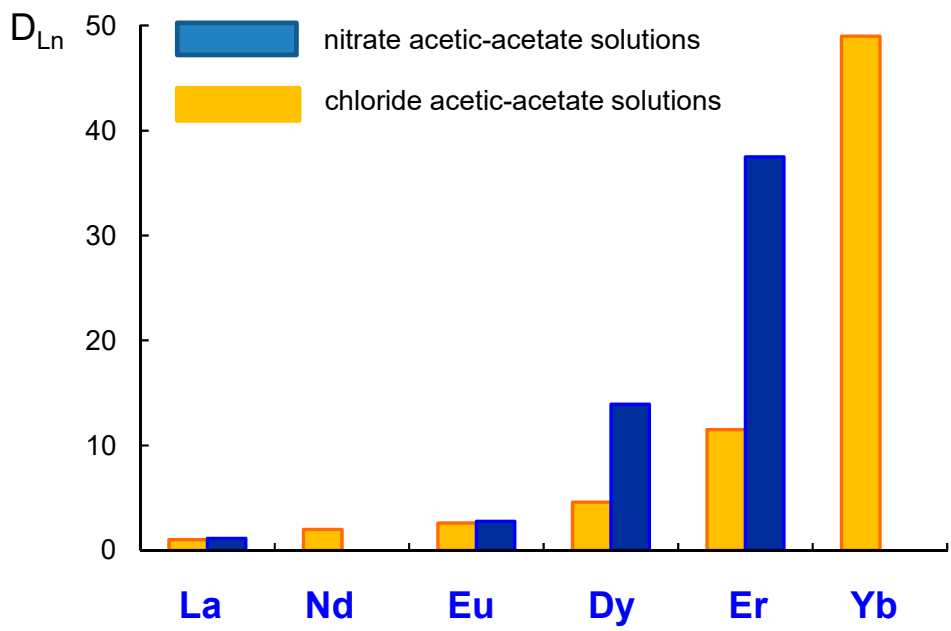

Figure 7. Extraction of lanthanides(III) with a mixture of $0.01 \mathrm{~mol} / \mathrm{L}$ Cyanex 272 and $0.03 \mathrm{~mol} / \mathrm{L}$ caprylic acid.

Table 2. Distribution ratios $\left(\mathrm{D}_{\mathrm{Ln}}\right)$ and separation factors $\left(\beta_{\mathrm{Ln} / \mathrm{La}}\right)$ of lanthanides(III) with a mixture of $0.01 \mathrm{~mol} / \mathrm{L}$ Cyanex 272 and $0.02 \mathrm{~mol} / \mathrm{L}$ caprylic acid.

\begin{tabular}{cccccc}
\hline \multicolumn{2}{c}{ Chloride Acetic-Acetate Media } & \multicolumn{3}{c}{ Nitrate Acetic-Acetate Media } \\
\hline Ln & $\mathbf{D}_{\text {Ln }}$ & $\beta_{\text {Ln/La }}$ & Ln & D $_{\text {Ln }}$ & $\beta_{\text {Ln/La }}$ \\
\hline $\mathrm{La}$ & 1.14 & - & $\mathrm{La}$ & 0.818 & - \\
\hline $\mathrm{Eu}$ & 2.75 & 2.41 & $\mathrm{Nd}$ & 1.0 & 1.22 \\
\hline $\mathrm{Dy}$ & 13.9 & 12.2 & $\mathrm{Eu}$ & 2.33 & 2.85 \\
\hline $\mathrm{Er}$ & 37.5 & 32.9 & $\mathrm{Dy}$ & 2.33 & 2.85 \\
\hline & & & $\mathrm{Yb}$ & 8.10 & 9.9 \\
\hline
\end{tabular}


Experimental conditions were as follows: aqueous phase $-0.2 \mathrm{~mol} / \mathrm{L}$ mixture of $\mathrm{NaOAc}$ and $\mathrm{AcOH}(2: 1) ; \mathrm{C}_{\mathrm{Ln}(\text { init }}=0.01 \mathrm{~mol} / \mathrm{L} ; \mathrm{pH}_{\text {eq. }}=5.8$. Experimental results indicated that, in this system, the separation of heavy lanthanides from light REE was possible.

\section{Conclusions}

This paper has described how a new extraction system containing mixtures of Cyanex 272 and caprylic acid in hexane was examined for $\mathrm{La}(\mathrm{III})$ extraction from chloride-acetate and nitrate-acetate media, as well as from acetic-acetate aqueous solutions. This system has the advantage of using commercially available extractants. The mixtures of Cyanex 272 and caprylic acid exhibited a high extraction ability and capacity. The extraction isotherms and the isomolar series data indicated that the $\mathrm{La}$ (III) extraction from chloride-acetate and nitrate-acetate solutions in this system proceeded through a cation-exchange mechanism, with the formation of lanthanum extracted species of the form $\mathrm{La}(\mathrm{OAc})_{2} \mathrm{~A} \cdot \mathrm{sH}_{2} \mathrm{~B}_{2}$ in the organic phase. The extraction of $\mathrm{La}$ (III) from acetic-acetate aqueous solutions proceeded with lower distribution ratios because of the decreasing equilibrium $\mathrm{pH}$ of the aqueous phase. It has been shown that the separation of lanthanides(III) can be achieved by extraction with synergistic Cyanex 272-caprylic acid mixtures in hexane from chloride acetic-acetate solutions. It was concluded that the extraction capacity of the investigated synergistic Cyanex 272-caprylic acid mixtures correlated with methods previously proposed. The usage of organic acidic agent mixtures, in particular a mixture of Cyanex 272 and caprylic acid in hexane, for the extraction and separation of rare earth metals from acetate and acetic-acetate solutions, is quite promising and may be of practical importance, for example, when carrying out processes in the multistage dynamic extraction mode.

Author Contributions: Conceptualisation, V.V.B. and Y.V.T.; methodology, V.V.B.; software, Y.V.T.; validation, V.K.I. and A.A.V.; formal analysis, Y.A.Z.; investigation, Y.V.T.; resources, V.V.B.; data curation, V.V.B.; writing — original draft preparation, V.V.B. and Y.V.T.; writing—review and editing, Y.A.Z. and A.A.V.; visualisation, V.V.B.; supervision, V.K.I.; project administration, A.A.V.; funding acquisition, V.K.I. All authors have read and agreed to the published version of the manuscript.

Funding: This work was supported by the Ministry of Science and Higher Education of the Russian Federation as part of the State Assignment of the Kurnakov Institute of General and Inorganic Chemistry of the Russian Academy of Sciences.

Conflicts of Interest: The authors declare no conflict of interest.

\section{References}

1. Zhou, J.; Leaño, J.L.; Liu, Z.; Jin, D.; Wong, K.; Liu, R.; Bünzli, J.G. Impact of Lanthanide Nanomaterials on Photonic Devices and Smart Applications. Small 2018, 14, 1801882. [CrossRef]

2. Binnemans, K.; Jones, P.T.; Blanpain, B.; Van Gerven, T.; Yang, Y.; Walton, A.; Buchert, M. Recycling of rare earths: A critical review. J. Clean. Prod. 2013, 51, 1-22. [CrossRef]

3. Shcherbakov, A.B.; Reukov, V.V.; Yakimansky, A.V.; Krasnopeeva, E.L.; Ivanova, O.S.; Popov, A.L.; Ivanov, V.K. CeO 2 NanoparticleContaining Polymers for Biomedical Applications: A Review. Polymers 2021, 13, 924. [CrossRef]

4. Yapryntsev, A.D.; Baranchikov, A.E.; Ivanov, V.K. Layered rare-earth hydroxides: A new family of anion-exchangeable layered inorganic materials. Russ. Chem. Rev. 2020, 89, 629-666. [CrossRef]

5. Shcherbakov, A.B.; Zholobak, N.M.; Spivak, N.Y.; Ivanov, V.K. Advances and prospects of using nanocrystalline ceria in cancer theranostics. Russ. J. Inorg. Chem. 2014, 59, 1556-1575. [CrossRef]

6. Belova, V.V.; Voshkin, A.A.; Egorova, N.S.; Khol'kin, A.I. Extraction of rare earth metals from nitrate solutions with a binary extractant based on Cyanex 272. Russ. J. Inorg. Chem. 2010, 55, 629-633. [CrossRef]

7. Xie, F.; Zhang, T.A.; Dreisinger, D.; Doyle, F. A critical review on solvent extraction of rare earths from aqueous solutions. Min. Eng. 2014, 56, 10-28. [CrossRef]

8. Fedorova, M.I.; Zakhodyaeva, Y.A.; Zinov'eva, I.V.; Voshkin, A.A. Recovery of rare-earth elements from nitrate solutions using polyethylene glycol 1500. Russ. Chem. Bull. 2020, 69, 1344-1348. [CrossRef]

9. Belova, V.V.; Egorova, N.S.; Voshkin, A.A.; Khol'kin, A.I. Extraction of rare earth metals, uranium, and thorium from nitrate solutions by binary extractants. Theor. Found. Chem. Eng. 2015, 49, 545-549. [CrossRef]

10. Chang, H.; Li, M.; Liu, Z.; Hu, Y.; Zhang, F. Study on separation of rare earth elements in complex system. J. Rare Earths. 2010, 28, 116-119. [CrossRef] 
11. Belova, V.V.; Voshkin, A.A.; Kholkin, A.I.; Payrtman, A.K. Solvent extraction of some lanthanides from chloride and nitrate solutions by binary extractants. Hydrometallurgy 2009, 97, 198-203. [CrossRef]

12. Sato, A.T. Liquid-liquid extraction of rare-earth elements from aqueous acid solutions by acid organophosphorus compounds. Hydrometallurgy 1989, 22, 121-140. [CrossRef]

13. Zhang, C.; Wang, L.; Huang, X.; Donga, J.; Long, Z.; Zhang, Y. Yttrium extraction from chloride solution with a synergistic system of 2-ethylhexylphosphonic acid mono-(2-ethylhexyl)ester and bis(2,4,4-trimethylpentyl)phosphinic acid. Hydrometallurgy 2014, 147-148, 7-12. [CrossRef]

14. Radhika, S.; Kumar, B.N.; Kantam, M.L.; Reddy, B.R. Liquid-liquid extraction and separation possibilities of heavy and light rare-earths from phosphoric acid solutions with acidic organophosphorus reagents. Sep. Purif. Technol. 2010, 75, 295-302. [CrossRef]

15. Pusparini, W.R.; Silfi, A.N.; Handini, T. Synergistic extraction of yttrium using mixtures of organophosphorus extractants. AIP Conf. Proc. 2021, 2381, 020065.

16. Jorjani, E.; Shahbazi, M. The production of rare earth elements group via tributyl phosphate extraction and precipitation stripping using oxalic acid. Arab. J. Chem. 2016, 9, S1532-S1539. [CrossRef]

17. Panda, N.; Devi, N.; Mishra, S. Solvent extraction of neodymium(III) from acidic nitrate medium using Cyanex 921 in kerosene. J. Rare Earths 2012, 30, 794-797. [CrossRef]

18. Tong, H.; Wang, Y.; Liao, W.; Li, D. Synergistic extraction of Ce(IV) and Th(IV) with mixtures of Cyanex 923 and organophosphorus acids in sulfuric acid media. Sep. Purif. Technol. 2013, 118, 487-491. [CrossRef]

19. Turanov, A.N.; Karandashev, V.K.; Boltoeva, M. Solvent extraction of intra-lanthanides using a mixture of TBP and TODGA in ionic liquid. Hydrometallurgy. 2020, 195, 105367. [CrossRef]

20. Kalyakin, S.N.; Kuzmin, V.I.; Mulagaleeva, M.A. Binary extraction of neodymium nitrate using 2-ethylhexylphosphonic acid 2-ethylhexyl mono ester and tri-n-octylamine. J. Mol. Liq. 2019, 273, 45-49. [CrossRef]

21. Belova, V.V.; Voshkin, A.A.; Egorova, N.S.; Kholkin, A.I. Solvent extraction of rare earth metals from nitrate solutions with di(2,4,4-trimethylpentyl)phosphinate of methyltrioctylammonium. J. Mol. Liq. 2012, 172, 144-146. [CrossRef]

22. Rout, A.; Binnemans, K. Solvent extraction of neodymium(III) by functionalized ionic liquid trioctylmethylammonium dioctyl diglycolamate in fluorine-free ionic liquid diluents. Ind. Eng. Chem. Res. 2014, 53, 6500-6508. [CrossRef]

23. Belova, V.V.; Martynova, M.M.; Tsareva, Y.V.; Baulin, V.E.; Baulin, D.V. Solvent extraction of lanthanum(III) from chloride and nitrate aqueous solutions with dioctyldiglycolamates of dioctylammonium and trioctylammonium. J. Mol. Liq. 2019, $293,111568$. [CrossRef]

24. Belova, V.V.; Tsareva, Y.V. Extraction and separation of lanthanides from aqueous chloride and nitrate media using mixtures of binary extractants based on secondary and tertiary amines. Mendeleev Commun. 2021, 31, 116-118. [CrossRef]

25. Quintriqueo, A.; Romero, J.; Quijada-Maldonado, E.; Bringas, E.; Olea, F.; Hernández, J. Extraction and separation factor for lanthanum(III) and cerium(III) complexes from aqueous medium using ionic liquid and kerosene. Adv. Chem. Eng. Sci. 2020, 10, 343-357. [CrossRef]

26. Pospiech, B.; Gega, J. Solvent extraction of metal ions from sulfate solutions obtained in leaching of spent Ni-MH batteries. New Trends Prod. Eng. 2019, 2, 214-221. [CrossRef]

27. Wang, X.; Li, W.; Li, D. Extraction and stripping of rare earths using mixtures of acidic phosphorus based reagents. J. Rare Earths 2011, 29, 413-415. [CrossRef]

28. Zhao, Q.; Li, Y.; Kuang, S.; Zhang, Z.; Bian, X.; Liao, W. Synergistic extraction of heavy rare earths by mixture of $\alpha-$ aminophosphonic acid HEHAMP and HEHEHP. J. Rare Earths 2019, 37, 422-428. [CrossRef]

29. Padhan, E.; Sarangi, K. Solvent extraction of praseodymium using different extractants-A synergistic study. Sep. Purif. Technol. 2018, 53, 295-302. [CrossRef]

30. Banda, R.; Jeon, H.S.; Lee, M.S. Solvent extraction separation of La from chloride solution containing Pr and Nd with Cyanex 272. Hydrometallurgy 2012, 121-124, 74-80. [CrossRef]

31. Wang, Y.L.; Liao, W.P.; Li, D.Q. A solvent extraction process with mixture of CA12 and Cyanex 272 for the preparation of high purity yttrium oxide from rare earth ores. Sep. Purif. Technol. 2011, 82, 197-201. [CrossRef]

32. Liu, Y.; Jeon, H.S.; Lee, M.S. Solvent extraction of Pr and Nd from chloride solution by the mixtures of Cyanex 272 and amine extractants. Hydrometallurgy 2014, 150, 61-67. [CrossRef]

33. Liu, Y.; Jeon, H.S.; Lee, M.S. Separation of Pr and Nd from La in chloride solution by extraction with a mixture of Cyanex 272 and Alamine 336. Met. Mater. Int. 2015, 21, 944-949. [CrossRef]

34. Quinn, J.E.; Soldenhoff, K.H.; Stevens, G.W.; Lengkeek, N.A. Solvent extraction of rare earth elements using phosphonic/phosphinic acid mixtures. Hydrometallurgy 2015, 157, 298-305. [CrossRef]

35. Wang, X.L.; Du, M.; Liu, H. Synergistic extraction study of samarium(III) from chloride medium by mixtures of bis(2,4,4trimethylpentyl)phosphinic acid and 8-hydroxyquinoline mixtures. Sep. Purif. Technol. 2012, 93, 48-51. [CrossRef]

36. Sun, X.; Wang, J.; Li, D.; Li, H. Synergistic extraction of rare earths by mixture of bis(2,4,4-trimethylpentyl)phosphinic acid and sec-nonylphenoxy acetic acid. Sep. Purif. Technol. 2006, 50, 30-34. [CrossRef]

37. Zaheri, P.; Abolghasemi, H.; Maraghe, M.G.; Mohammadi, T. Intensification of europium extraction through a supported liquid membrane using mixture of D2EHPA and Cyanex 272 as carrier. Chem. Eng. Process. 2015, 92, 18-24. [CrossRef] 
38. Zhang, F.; Wu, W.; Dai, J.; Bian, X. Extraction and separation of Pr(III)/Ce(III) from chloride medium by 2-ethylhexylphosphonic acid mono-(2-ethylhexyl) ester in the presence of two complexing agents. Sep. Purif. Technol. 2016, 51, 778-783. [CrossRef]

39. Yin, S.; Wu, W.; Bian, X.; Zhang, F. Effect of complexing agent lactic acid on the extraction and separation of Pr(III)/Ce(III) with di-(2-ethylhexyl) phosphoric acid. Hydrometallurgy 2013, 131-132, 133-137. [CrossRef]

40. Kashi, E.; Habibpour, R.; Gorzin, H.; Maleki, A. Solvent extraction and separation of light rare earth elements (La, Pr and Nd) in the presence of lactic acid as a complexing agent by Cyanex 272 in kerosene and the effect of citric acid, acetic acid and Titriplex III as auxiliary agents. J. Rare Earths 2018, 36, 317-323. [CrossRef]

41. Saleh, M.I.; Bari, M.F.; Saad, B. Solvent extraction of lanthanum(III) from acidic nitrate-acetato medium by Cyanex 272 in toluene. Hydrometallurgy 2002, 63, 75-84. [CrossRef]

42. Zanonato, P.L.; Bernardo, P.; Bismondo, A.; Rao, L.; Choppin, G.R. Thermodynamic studies of the complexation between neodymium and acetate at elevated temperatures. J. Sol. Chem. 2001, 30, 1-18. [CrossRef]

43. Kalyakin, S.N.; Kuz'min, V.I.; Mulagaleeva, M.A. Binary extraction of lanthanide (III) chlorides using carboxylates and dialkylphosphates of secondary and tertiary amines. Hydrometallurgy 2015, 151, 116-121. [CrossRef]

44. Kalyakin, S.N.; Kuzmin, V.I.; Mulagaleeva, M.A. Binary extraction of lanthanides (III) nitrates with carboxylates and dialkylphosphates of secondary and tertiary amines. Theor. Found. Chem. Eng. 2016, 50, 878-883. [CrossRef] 